\title{
The dual role of Andean topography in primary divergence: functional and neutral variation among populations of the hummingbird, Metallura tyrianthina
}

Phred M. Benham ${ }^{1,2^{*}}$ and Christopher C. Witt ${ }^{1}$

\begin{abstract}
Background: The ridges and valleys of the Andes create physical barriers that limit animal dispersal and cause deterministic local variation in rainfall. This has resulted in physical isolation of animal populations and variation in habitats, each of which has likely contributed to the evolution of high species diversity in the region. However, the relative influences of geographic isolation, ecoclimatic conditions, and their potential interactions remain poorly understood. To address this, we compared patterns of genetic and morphological diversity in Peruvian populations of the hummingbird Metallura tyrianthina.

Results: Phylogenetic and variation partitioning analyses showed that geographic isolation rather than climatic dissimilarity explained the greatest proportion of genetic variance. In contrast, bill length variation was explained by climatic seasonality, but not by genetic divergence. We found that mutation-scaled migration rate $(m)$ between persistently humid and semi-humid environments was nearly 20 times higher when the habitats were contiguous $(m=39.9)$ than when separated by a barrier, the Cordillera de Vilcanota $(m=2.1)$. Moreover, the population experiencing more gene flow exhibited a lesser degree of bill length divergence despite similar differences in climate.

Conclusions: Geographic isolation is necessary for genetic divergence. Ecological differences, represented here by climate characteristics, are necessary for functional divergence. Gene flow appears to hinder the evolution of functional traits toward local adaptive optima. This suggests that functional diversification requires geographic isolation followed or accompanied by a shift in ecological conditions. Andean topography causes both isolation and climatic variation, underscoring its dual role in biotic diversification.
\end{abstract}

Keywords: Andes, Ecological speciation, Geographic speciation, Bill morphology, Trochilidae

\section{Background}

The tropical Andes harbor a significant fraction of global diversity (e.g., $15 \%$ of land plant species), with half this diversity comprised of regional endemics [1]. In contrast to other diverse montane regions (e.g. the Himalayas [2]), a major fraction of Andean diversity is derived from lineages that have radiated extensively in situ [3-9]. Thus, identifying the historical and landscape characteristics that

\footnotetext{
* Correspondence: phred.benham@umconnect.umt.edu

'Department of Biology and Museum of Southwestern Biology, University of New Mexico, 167 Castetter Hall MSC03 2020, 1 University of New Mexico, Albuquerque, NM 87131, USA

${ }^{2}$ Present address: Division of Biological Sciences, University of Montana, 32 Campus Dr. HS104, Missoula, MT 59812, USA
}

foster speciation in the Andes will be crucial for understanding the mechanisms that have made the region a diversification hotspot. The topographically complex Andean landscape seems to drive diversification in two ways [10]. First, topographic barriers can fragment the narrow distributions of montane taxa and promote divergence via allopatric speciation [11-15]. Second, topography creates climate variation over small spatial scales that can drive ecological divergence, leading to reproductive isolation [16-18] and/or accelerated niche divergence [19]. Although some evidence for both mechanisms operating in the Andes exists, the relative importance of each 
mechanism working independently or in concert during the diversification process remains poorly understood.

Topographic barriers are frequently associated with phenotypic and genetic discontinuities in Andean species, providing evidence for the importance of physical isolation in Andean diversification (e.g., [20-22]). However, if physical isolation across topographic barriers were the sole driver of Andean speciation, species-level differences would be expected to accumulate via neutral processes. Substantial empirical evidence supports non-neutral mechanisms of speciation [23], although the overall tempo of diversification in the tree of life has recently been interpreted as evidence of neutral diversification [24]. Discordant patterns of phenotypic and genetic diversity are frequently found in Andean lineages, in contrast to neutral expectations ([4, 25-27], but see [22]). Moreover, coalescent simulations of plumage evolution in Arremon brushfinches indicate that plumage differentiation proceeds at a much faster rate than expected via neutral divergence [28]. In sum, it seems that range fragmentation alone is an insufficient mechanism for explaining the generation of Andean diversity.

Ecological speciation occurs when ecological factors, regardless of gene flow, catalyze reproductive isolation by natural selection [18]. In the Andes, higher diversification rates are associated with climatic-niche shifts indicating that ecoclimatic variation may be an important driver of lineage proliferation [29]. Several studies of Andean taxa have found morphometric and functional divergence arising among populations distributed along ecological gradients in the face of ongoing gene flow [30-35]. Although these results suggest that ecological mechanisms might be the primary drivers of divergence in the region, abundant evidence from outside the Andes indicates that rates of phenotypic divergence and evolution of reproductive isolation will be slower in populations experiencing gene flow relative to those that are more isolated (e.g., [17, 36-38]). Indeed, studies examining whether sister species replace one another along ecological gradients in the Andes have been inconclusive, with some sister species found to replace one another along ecological gradients in Andean butterflies [6] and frogs [39], but not in Andean birds or mammals [40-44].

Given the lack of clear support for an exclusive role of geographic isolation or ecological speciation in driving Andean diversification, a better understanding of the speciation process in the Andes will likely come from addressing how geographic and ecological isolation operate in concert $[12,15]$. The topographic complexity of the region should allow for interactions between these two processes. Topographic barriers promote the reduction of gene flow, while the increased climatic variation associated with topography potentially increases the tempo of divergence via differential selection pressures $[19,45,46]$. One approach to test whether divergence is associated with topographic relief will be to assay divergence among population pairs that (i) occupy similar climates on either side of a topographic barrier, (ii) occupy different climates on either side of a topographic barrier, and (iii) occupy different climates in the absence of a topographic barrier. In particular, comparing patterns of spatial variation in effectively neutral genetic markers and functional traits will provide a means to understand the relative influence of geographic and ecological isolation in promoting genetic structure and divergence in ecologically relevant traits.

We focus on Peruvian populations of the Andean hummingbird Metallura tyrianthina to understand the drivers of spatial diversity in functional morphology and genetics. The geological history of the Peruvian Andes generated a topographically complex landscape, with glaciated cordilleras $>5000 \mathrm{~m}$ in elevation interspersed with deep river valleys [47]. These landscape features generated habitat discontinuities in the elevational distribution of $M$. tyrianthina (1900-4200 m [48]). Final uplift of the central Andes over the last $\sim 10 \mathrm{Myr}$ also dramatically altered the climate [49], generating a steep rainfall gradient from the wet eastern slope to the desert-like western slope [50]. M. tyrianthina likely colonized Peru from northern populations $\sim 2 \mathrm{Ma}$ and presently spans several topographic barriers and steep climatic gradients in the Peruvian Andes [51]. Three subspecies of Metallura tyrianthina occur in Peru: M. t. tyrianthina north and west of the Marañón valley in humid montane forests and edge habitat; $M$. t. septentrionalis in semi-humid montane scrub along the Western Cordillera of Peru south to the department of Lima; and M. t. smaragdinicollis throughout the eastern Andes of Peru in humid forests along east-facing slopes and in semi-humid scrub on west-facing and rain-shadowed slopes (Fig. 1a [48]).

We compared spatial patterns of variation in bill length and effectively neutral DNA sequences in $M$. tyrianthina to test predictions derived from models of geographic speciation, ecological speciation, or a combination. (1) If geographic isolation drives divergence then we will expect to find a concordant relationship between phenotypic and genetic divergence across topographic barriers. However, (2) if divergence is primarily driven by ecological factors then we expect to find linked phenotypic and genetic divergence in association with ecological dissimilarities, independent of geographic isolation. Finally, (3) if topographic barriers and ecological differences interact to drive divergence then we expect to find phenotypic divergence between different environments, but only when a topographic barrier that reduces gene flow separates those environments.

\section{Methods}

\section{Sampling}

Tissue samples of Metallura tyrianthina were obtained from frozen tissue collections at natural history museums, primarily the Museum of Southwestern Biology 


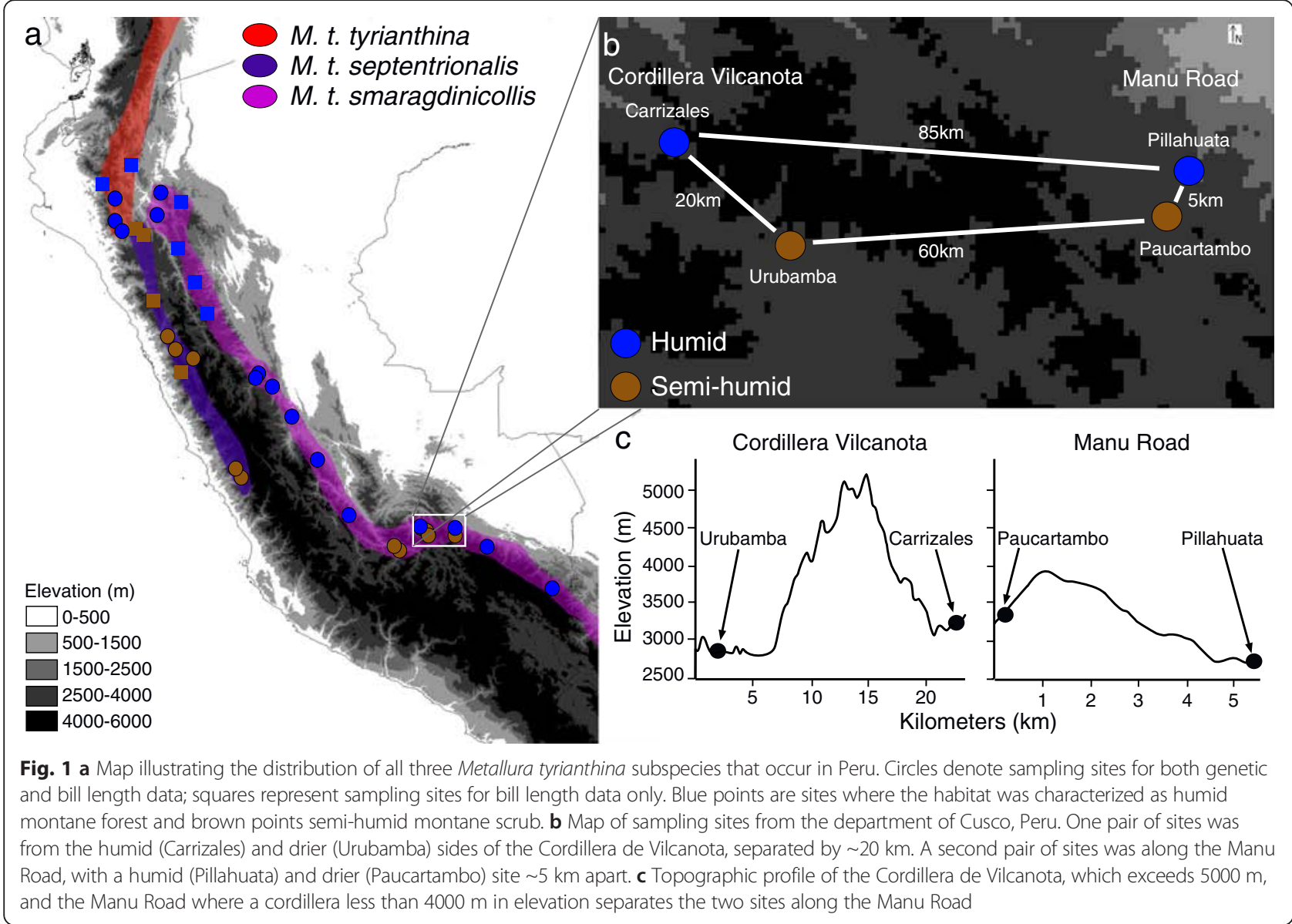

(110 individuals). Collection of these samples was approved by the University of New Mexico Institutional Animal Care and Use Committee (protocol no. 08UNM033-TR-100117) and permitted by Peruvian management authorities (permit nos. 76-2006-INRENA-IFFS-DCB， 004-2007-INRENAIFFS-DCB, 135-2009-AG-DGFFS-DGEFFS, 0377-2010-AGDGFFS-DGEFFS，0199-2012-AG-DGFFS-DGEFFS， and 006-2013-MINAGRI-DGFFS/DGEFFS). The geographic breadth of sampling was increased through tissue loans of an additional 26 individuals from other natural history collections (Additional file 1: Table S1). From all 136 individuals, we extracted genomic DNA from pectoral muscle that was either frozen or preserved in RNAlater $^{\oplus}$ (Life Technologies) using a Qiagen DNeasy blood and tissue kit and following the manufacturer's protocols (Qiagen, Valencia, CA, USA). The mitochondrial gene NADH dehydrogenase, subunit 2 (ND2) was sequenced for all 136 individuals. For all of the 47 individuals sampled in the department of Cusco we sequenced an additional two nuclear introns: Adenylate Kinase, intron 5 (AK1) and $\beta$-fibrinogen, intron 7 (Bfib7); and the Z-linked locus Muscle, Skeletal, Tyrosine Receptor Kinase (MUSK). Primers and sequencing protocols were identical to those used in Benham et al. [51]. All sequences were manually assembled and edited using Sequencer v. 4.10.1 (Gene Codes Corporation, Ann Arbor, MI, USA) and aligned using MUSCLE v. 3.7 [52]. Haplotype reconstruction for nuclear loci with multiple double peaks was conducted using the program PHASE v. 2.1.1 [53, 54].

The size and shape of hummingbird bills vary in association with floral resources $[55,56]$ and competitive interactions with other hummingbirds [57]. The hummingbird bill is an ideal trait in which to examine functional diversification across the Andean landscape due to its functional importance and the fact that bill characteristics tend to be highly heritable [58]. We measured bill length (exposed culmen) to the nearest $0.01 \mathrm{~mm}$ using digital calipers on 245 museum specimens collected from throughout Peru (Fig. 1a; Additional file 1: Table S1). All specimens included in this study were associated with precise locality and mass data and all measurements were made on dried specimens to avoid increased error from specimen shrinkage [59]. Sexual dimorphism in bill length and shape is widely encountered within Trochilidae [60, 61]; however, using a two-tailed $t$-test for the entire dataset, we did not detect any significant differences between the sexes in bill length; accordingly, males and females were pooled for subsequent analyses. All statistical analyses were 
conducted using the open source program R (http:// www.r-project.org/).

To assess environmental differences among all specimen localities we obtained bioclimatic data at 30-s resolution from the WorldClim dataset [62]. Using coordinates for each sampling locality we extracted data from gridfiles of the BioClim variables within the program DIVA-GIS (http://www.diva-gis.org/). The climatic data includes 19 variables related to measures of temperature, precipitation and seasonality (Additional file 1: Table S2). These data are derived from interpolated climate surfaces available for the entire globe at 30 -arc sec spatial resolution and were gathered from several independent sources between 1950 and 2000 [62]. Although the WorldClim dataset may be error-prone in montane regions due to interpolation [62], such error is likely to be random with respect to our hypotheses. The WorldClim dataset has been used successfully in a number of modeling and morphological studies of Andean birds (e.g., [63-65]). WorldClim data has also been used successfully at fine spatial scales to guide surveys for range-restricted Andean hummingbird species [66]. We divided the 19 BioClim variables into three groups each corresponding to variables related to temperature, precipitation, and seasonality. Secondly, we performed a principal components analysis on each of the three groups and used the first components of temperature (83.7\% of the variance), precipitation (78.0 \%), and seasonality (82.9\%), respectively, for analyses (Additional file 1 : Table S2).

\section{Influence of topographic barriers on divergence}

To assess the association of genetic structure with topographic barriers we constructed a phylogeny of all Metallura tyrianthina ND2 samples using Bayesian methods in MrBayes v. 3.1 [67] on the CIPRES Science Gateway [68]. For an outgroup we obtained ND2 data of Metallura phoebe from GenBank (Ascension number: EU042569.1). A GTR $+I+\Gamma$ model was selected as the most appropriate substitution model based on Akaike Information Criteria [69] estimated in jmodeltest v. 0.1 [70, 71]. We also partitioned the dataset by codon position following McGuire et al. [5]. The MCMC analysis ran for 40 million generations sampling every 1000 generations and consisted of four simultaneous runs of four chains each with a temperature for heated chains of 0.175 . We assessed convergence using the program AWTY [72] and discarded the first $10 \%$ of trees as burnin. To further evaluate patterns of genetic structure we calculated the number of haplotypes for ND2 in DNaSP [73] and visualized these as a haplotype network using a median-joining method in NETWORK v. 4.6.10 [74].

We evaluated the proportion of genetic diversity explained by topographic barriers as identified with phylogenetic and network analyses in Peruvian Metallura tyrianthina using an AMOVA analysis. For this analysis we divided the sampled individuals into six groups each divided by a topographic barrier. These barriers include: the North Peru Low, high Andean ridgeline, the Mantaro valley, the Apurímac valley, and the Cordillera de Vilcanota (Fig. 2c). These barriers also correspond to phenotypic and genetic discontinuities in other Andean bird species (e.g., $[20,75])$. Degree of divergence among clades was assessed with Fst values and Nei's average corrected pairwise differences $\left(D_{A}[76]\right)$, which accounts for intrapopulation polymorphism with the equation $\mathrm{D}_{\mathrm{A}}=\mathrm{d}_{\mathrm{xy}}-0.5$ $\left(d_{x}-d_{y}\right)$, where $x$ and $y$ are the two populations compared and $\mathrm{d}$ is the average uncorrected genetic differences. For each of the clades identified using the above analyses we also calculated standard indices of molecular diversity, including nucleotide and haplotype diversity. Finally, we calculated Tajima's D and Fu's F (1000 simulations) to determine whether any of the ND2 clades exhibit deviations from neutrality. All population genetic analyses were performed in the program Arlequin v. 3.5 [77].

\section{Concordance between genetic and morphological divergence}

To test for concordance between patterns of genetic divergence and bill length variation we compared bill length differences to two measures of genetic divergence, $\mathrm{D}_{\mathrm{A}}$ and linearized Fst (equal to Fst/1-Fst [78]), across sixteen sampling localities. These measures of genetic distance were compared to the average difference in bill length between each pair of sampling localities. We used a series of linear regression analyses to compare genetic and bill length differences among all pairwise comparisons of populations, among populations in humid montane forest habitats, in semi-humid montane scrub habitats, and among populations distributed in different habitat types (Fig. 1a).

\section{Climatic drivers of divergence}

Populations distributed across different climatic regimes could experience adaptive divergence that will have a negative influence on gene flow leading to reproductive isolation and genetic divergence even at neutral loci, a process referred to as isolation by environment (IBE [18, 79-81]). We test for IBE in Metallura tyrianthina by comparing the relative roles of climatic distance and geographic distance in shaping patterns of genetic variation using a variation partitioning method in the R-package 'vegan' [82]. Variation partitioning utilizes canonical redundancy analysis to dissect the contributions of different explanatory factors (e.g. climate, geographic distance) to variation in a response variable (e.g., genetic distance [83]). Variation partitioning has been shown to perform similarly to other recently developed tests for teasing apart spatially autocorrelated drivers of genetic diversity [80] and performs better 


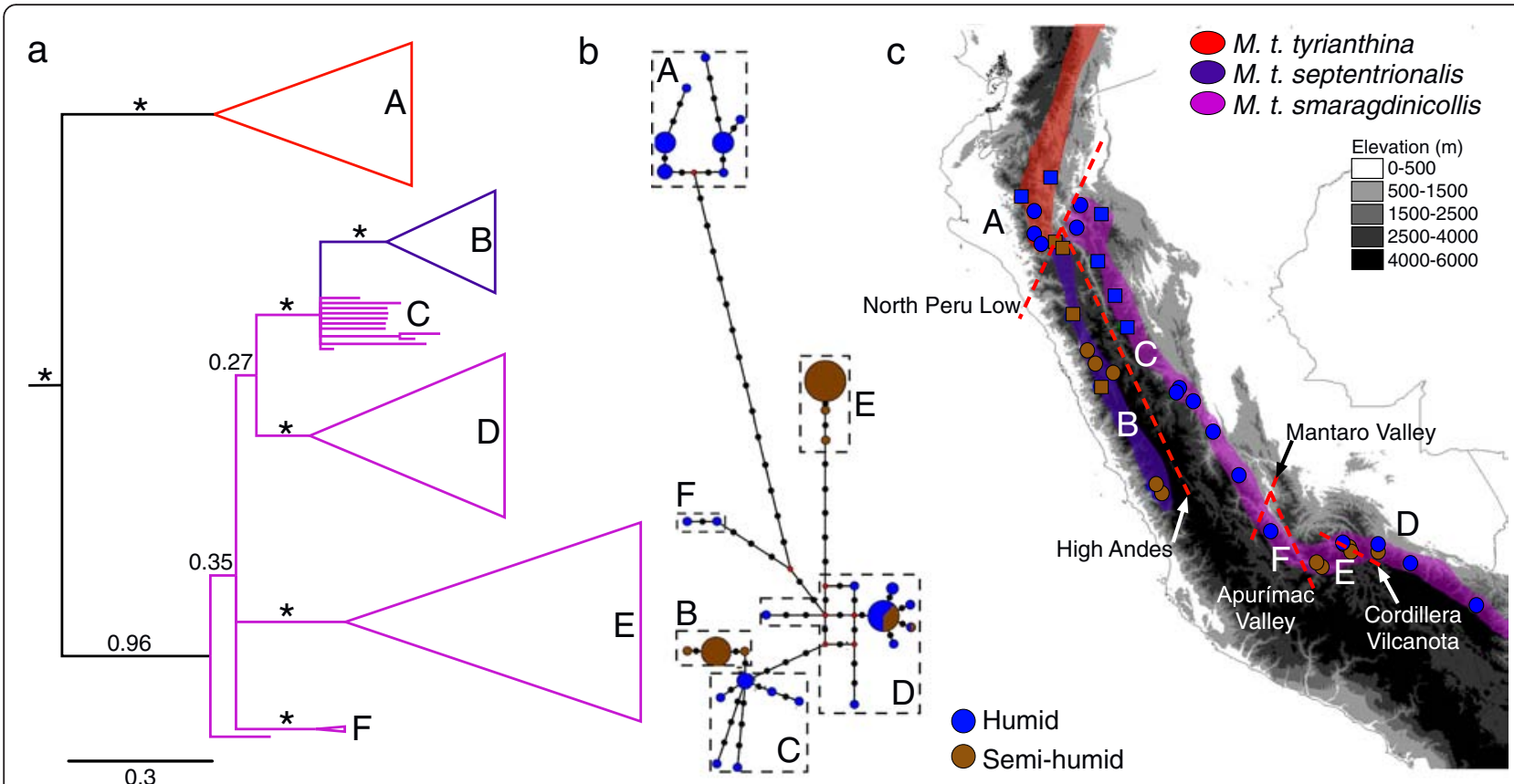

Fig. 2 a ND2 Bayesian phylogeny for Peruvian populations of Metallura tyrianthina. Posterior probabilities for each node printed above branches (* signifies 1.0 pp). The six geographically structured clades are lettered on all figures. Each clade is colored by subspecies as in panel c. b Median-joining haplotype network of ND2. Brown color indicates semi-humid montane scrub habitat; blue indicates humid montane forest. c Geographic distribution of each clade (A-F). Red dotted lines signify putative physical barriers that isolate the six clades

than partial Mantel tests, which can exhibit a high type I error rate when considering spatially autocorrelated data $[81,84,85]$. For M. tyrianthina we assessed the influence of environmental variation on genetic distance as measured by $\mathrm{D}_{\mathrm{A}}$ and linearized Fst. We used Euclidean geographic distances among sampling localities to assess the role of geographic isolation. To assess the role of climate, we performed principal components analysis on all 19 BioClim variables from the 16 sampling sites for which we had both genetic and bill length data to reduce these variables to two principal components. The first principle component explained $93.13 \%$ of BioClim variation, with the heaviest loading linked to annual precipitation. The second principle component explained $4.55 \%$ of BioClim variation, with the heaviest loading associated with precipitation in the wettest quarter (Additional file 1: Table S3). As alternative climatic variables, we used the first principle components of the BioClim variables for temperature, seasonality, and precipitation, respectively. Using either $\mathrm{D}_{\mathrm{A}}$ or linearized Fst we performed a series of variation partitioning analyses using all potential combinations of climatic principal components plus geographic distance as the explanatory variables (Table 1 ). We then tested whether the fraction of variation explained by each climatic variable was significant when conditioned for geography, and vice versa, using a permutation analysis with the 'anova' function in the vegan package $(10,000$ permutations).

We tested the influence of different climatic variables on bill length variation throughout Peru using an information-theoretic approach. We performed regression analyses with bill length as the dependent variable and $\mathrm{PC} 1$ of temperature, precipitation, and seasonality, respectively, as explanatory variables. We also explored the possibility of using $\mathrm{PC} 1$ and $\mathrm{PC} 2$ of all 19 BioClim variables as predictors; however, PC1 and PC2 were found to be strongly correlated with seasonality and temperature, respectively (correlation coefficient $>0.95$ for both). Consequently, we excluded PC1 and PC2 predictors to avoid issues associated with multi-collinearity in downstream analyses. Finally, we also include body mass in this analysis as another potential predictor of bill length variation. We evaluated 15 models representing all possible main effect combinations of predictor variables and included an additional six models to evaluate all possible pairwise interactions between the four variables. The likelihood of all 21 models was evaluated using an Akaike Information Criterion corrected for sample size (AICc). Each model was ranked using $\triangle \mathrm{AICc}$ and Akaike weights [86] to determine which of our hypothesized climatic models best explains bill length variation in Peru. We discarded models from consideration if a nested model (containing a 
Table 1 Proportion of genetic variance explained by geographic or climatic variation

\begin{tabular}{|c|c|c|c|c|c|c|}
\hline \multirow[b]{2}{*}{ Model } & \multicolumn{3}{|l|}{$D_{A}$} & \multicolumn{3}{|l|}{ Fst/(1-Fst) } \\
\hline & Geography & Climate & Shared & Geography & Climate & Shared \\
\hline geog + [clim1,clim2] & 0.4001 & -0.0278 & 0.0660 & 0.1557 & 0.0078 & 0.0969 \\
\hline geog + clim1 & $0.4838^{*}$ & 0.0102 & -0.0176 & 0.2332 & 0.0578 & 0.0194 \\
\hline geog + clim2 & $0.3392^{*}$ & -0.0841 & 0.1270 & 0.1010 & -0.1316 & 0.1516 \\
\hline geog + [temp,seas,prec] & $0.8526^{* * *}$ & $0.4035^{*}$ & -0.3864 & 0.2404 & 0.1287 & 0.0122 \\
\hline geog + prec & $0.4832^{*}$ & 0.0095 & -0.0170 & 0.2321 & 0.0569 & 0.0205 \\
\hline geog + seas & $0.4865^{*}$ & 0.054 & -0.0204 & 0.3068 & 0.0545 & -0.0545 \\
\hline geog + temp & $0.4917^{*}$ & -0.0295 & -0.0256 & 0.2047 & -0.0928 & 0.0479 \\
\hline geog + [prec,seas $]$ & 0.3636 & -0.047 & 0.1026 & 0.1007 & -0.0349 & 0.1518 \\
\hline geog + [prec,temp] & 0.5093 & -0.0238 & -0.0432 & 0.1870 & -0.0294 & 0.0655 \\
\hline geog + [seas,temp] & $0.6909^{* * *}$ & 0.2009 & -0.2248 & 0.3160 & 0.0240 & -0.0635 \\
\hline
\end{tabular}

Geographic distance (geog) is the Euclidean distance among sampling sites and climate is the proportion of variance explained by the different climatic variables included in each model. Clim 1 and clim 2 are the first two principal components of the entire 19 variable BioClim dataset, explaining $97 \%$ of the variance in total. Temp, seas, and prec are the first principal components for temperature, seasonality, and precipitation BioClim variables, respectively. The proportion of variance shared by both geography and climate is reported in the columns labeled 'shared'. High 'shared' values would indicate collinearity between ecological and geographic parameters; negative values are an artifact of subtracting adjusted $\mathrm{R}^{2}$ values to derive the shared proportion of variance [83]

${ }^{*} p<0.5$; ${ }^{* *} p<0.01$; ${ }^{* * *} p<0.001$

subset of the same parameters) had a better AICc score [87].

\section{Dual influence of topography on divergence}

We assess the combined influence of topographic barriers and climatic differences in shaping patterns of genetic and morphological divergence across two pairs of populations in which the members of each pair are adjacent but occur in different environments (Fig. 1b). The first pair of populations were $20 \mathrm{~km}$ apart on either side of the Cordillera de Vilcanota with one population sampled in the semi-humid scrub of the Urubamba valley $(n=21$; elevation range $3380-4200 \mathrm{~m})$ and the second within humid montane forest near the town of Carrizales ( $n=6$; elevation: 3201-3552 m). A second pair of populations was distributed along the Manu Road only $5 \mathrm{~km}$ apart with birds sampled in the semi-humid scrub near the town of Paucartambo $(n=7$; elevation $3360 \mathrm{~m})$ and in humid montane forest near Pillahuata $(n=13$; elevation $2500-3350 \mathrm{~m}$ ). The Cordillera de Vilcanota is glaciated and exceeds $5000 \mathrm{~m}$ elevation, with passes as low as $4300 \mathrm{~m}$; whereas the pass separating humid and semihumid populations along the Manu Road is only $3900 \mathrm{~m}$ (Fig. 1c). Given that the typical elevational distribution of M. tyrianthina is $1900-4200 \mathrm{~m}$ [46] the Cordillera de Vilcanota likely imposes a more significant barrier to gene flow then any ridge along the Manu Road. We used a oneway ANOVA and TukeyHSD test to examine differences in bill length among the four sites. To determine how our small sample sizes for the Carrizales $(n=6)$ and Paucartambo $(n=7)$ populations would impact our statistical power, we performed a power analysis in the $\mathrm{R}$ package pwr (https://cran.r-project.org/web/packages/ pwr/index.html). For this analysis we first performed two $t$-tests comparing bill length differences across the Cordillera de Vilcanota and the Manu Road. The results of these t-tests were used to estimate the effect size of bill length divergence between both humid and semi-humid population pairs. Given the calculated effect of habitat on bill length divergence across both population pairs we confirmed that the statistical power using our small sample sizes exceeded the $a$ priori defined threshold of 0.8 (i.e., $>80 \%$ probability of rejecting the null hypothesis if it is false).

To assess patterns of genetic divergence among sampling localities we calculated all pairwise Fst-values across the four sampled populations for each of the four loci in Arlequin v.3.5 [77]. Secondly, we determined levels of gene flow among the four populations using the program IMa2 [88]. IMa2 is a coalescent genealogy sampler that simultaneously estimates effective population size, migration rates, and divergence times within the framework of an isolation with migration model [89]. The IMa2 program assumes no recombination and before analyses we assessed patterns of recombination in the nuclear loci using the four-gamete test [90] in DnaSp [73]. This test detected recombination in regions of both $A K 1$ and Bfib7. We saved the longest segment of each gene exhibiting no evidence of recombination, leaving segments of $232 \mathrm{bp}$ for $A K 1$ and $313 \mathrm{bp}$ for Bfib7. We conducted pairwise comparisons between humid and semi-humid populations distributed along the Manu Road and across the Cordillera de Vilcanota. Additionally, we ran analyses comparing the two humid populations and the two semi-humid populations. For each locus we specified a mutation rate with error (equal to mutations per locus per year $(\mu / \mathrm{l} / \mathrm{y}))$ derived from a multi-locus dataset analyzed in "BEAST using both geological and fossil 
calibrations for hummingbirds [51]. These mutation rates were: ND2: $9.5 \times 10^{-6} \mu / 1 / y\left(95 \%\right.$ HPD: $7.5 \times 10^{-6}$, $\left.1.2 \times 10^{-5} \mu / \mathrm{l} / \mathrm{y}\right) ; A K 1: 1.0 \times 10^{-6} \mu / \mathrm{l} / \mathrm{y}(95 \%$ HPD: $\left.7.0 \times 10^{-7}, 1.3 \times 10^{-6} \mu / \mathrm{l} / \mathrm{y}\right) ;$ Bfib7: $1.3 \times 10^{-6} \mu / \mathrm{l} / \mathrm{y}$ (95\% HPD: $8.5 \times 10^{-7}, 1.6 \times 10^{-6} \mu / \mathrm{l} / \mathrm{y}$ ); and MUSK: $9.8 \times 10^{-7} \mu / \mathrm{l} / \mathrm{y}\left(95 \%\right.$ HPD: $\left.6.4 \times 10^{-7}, 1.2 \times 10^{-6} \mu / \mathrm{l} / \mathrm{y}\right)$. We applied inheritance scalars to each locus (ND2: 0.25 ; MUSK: $0.75 ; A K 1: 1.0 ; B f i b 7: 1)$ to account for variation in effective population sizes. Benham et al. [51] hypothesized that Metallura tyrianthina colonized southern Peru $\sim 2 \mathrm{Ma}$ (95 \% HPD: 1-3 Ma) based on a time-calibrated phylogeny. We use the upper bound of the $95 \%$ HPD from this previous analysis to set the prior for divergence time in all analyses as $t=3 \mathrm{Ma}$. We constrained the migration rate parameter $m$ to be symmetric to reduce the number of parameters, as preliminary analyses estimating asymmetric migration rates were poorly resolved. We also ran several preliminary runs with large, flat priors to estimate migration rate and population size [91]. Based on these preliminary analyses, we set the upper bound of a uniform prior that included the entire posterior distribution of each parameter (Additional file 1: Table S4). Preliminary analyses were unable to resolve $q$ for the ancestral population $\left(\theta_{\mathrm{A}}\right)$; accordingly, we followed Peters et al. [92] by setting the upper bound of $\theta_{\mathrm{A}}$ to be greater than the sum of $\theta$ for the two sampled populations. For all four comparisons, we ran three independent MCMC analyses to ensure convergence on similar parameter estimates. We also evaluated stationarity of the MCMC analyses by checking whether ESS was >150 for all parameters and examining plots generated by the program for $\log [P(G)+P(D \mid G)]$ for evidence of long term trends. Runs ran for $10^{5}$ steps of burnin and at least $10^{7}$ steps post-burnin, sampling every 100 steps to generate $10^{5}$ genealogies. For all runs, we employed a geometric heating scheme with 50 heated chains.

\section{Results}

\section{Sequence characteristics}

ND2 sequences were $1041 \mathrm{bp}$ in length and included 76 informative sites (7.3\%). A $90 \mathrm{bp}$ indel in the $A K 1$ intron and a 15 bp indel found in the Bfib7 intron were removed before any analyses were conducted, leaving: 337 bp of $A K 1$ (four informative sites-1.2 \%), 629 bp of Bfib7 (five informative sites-0.8\%), and 594 bp of MUSK (four informative sites $-0.7 \%)$. There were no internal stop codons, indels, or anomalous substitution patterns in the ND2 sequences that might indicate amplification of pseudogenes. However, we excluded one sample (FMNH 433155) because it did not align with other sequences and BLAST returned ambiguous matches with a variety of hummingbird species. Mitochondrial and nuclear intron sequence data have been deposited on GenBank, accession numbers: KU527140-KU527416.

\section{Geographic isolation}

Seven well-supported mitochondrial clades (posterior probability $>0.9$ ) were recovered in the Bayesian phylogeny (Fig. 2a). This structure only corresponds to the populations sampled in Peru and more extensive phylogeographic structure exists within this species in the northern Andes [51]. The nominate subspecies consists of one clade (A) isolated by the North Peru Low and $>2 \%$ divergent from all other populations (Additional file 1: Table S5). Topographic barriers were associated with phylogenetic structure among all other clades, including: M. $t$. septentrionalis, on the west side of the central Andes (clade B), which is $0.24 \%$ divergent from a northern clade of M. t. smaragdinicollis on the east side of the central Andes (clade C); clade D of southeastern Peru, which is isolated from clade E (0.91 \% divergent), of the upper Apurímac and Urubamba valleys, by the Cordillera de Vilcanota; and finally, an Ayacucho population (clade F) that is bounded by the Mantaro River to the north $(0.67 \%$ divergent) and the Aprurímac River to the south (0.79$1.04 \%$ divergent). Some structure was also detected within clade $\mathrm{C}$ potentially due to the influence of the Huallaga Valley or isolation by distance. Fst values largely corresponded to corrected pairwise differences among clades (Additional file 1: Table S5). A single individual from the same locality as clade D showed closer affinities to an extra-limital haplogroup from Bolivia (see [51]). Haplotype networks reaffirmed the prominent role of physical barriers in structuring neutral genetic diversity. Haplotype structure between the humid montane forest and semi-humid montane scrub habitats only existed in conjunction with physical barriers. Within clade D, birds from both humid and semi-humid habitats shared identical mtDNA haplotypes (Fig. 2b). Finally, using an AMOVA analysis we found that $88.1 \%$ (d.f. 6; sum of squares 735.2; variance 6.8) of the genetic variance within Peruvian $M$. tyrianthina corresponds to the barriers highlighted in red (Fig. 2c) and only $9.4 \%$ (d.f. 120; sum of squares 86.7; variance 7.2) of the genetic variation is found within groups between topographic barriers (Additional file 1: Table S6). Nucleotide diversity was highest in clades A and C. Only clade D exhibited significant deviations from neutrality based on both Fu's F and Tajima's D. Clade $\mathrm{B}$ also exhibited significant Fu's $\mathrm{F}$ and clades $\mathrm{A}$ and $\mathrm{C}$ exhibited significant Tajima's D (Additional file 1: Table S7). Deviations from neutrality in these clades may reflect the recent expansion of the species into the central Andes [51] or subtle geographic structure among sampling localities within these clades.

\section{Ecological divergence}

Results of variation partitioning analyses corroborated a strong role for isolation by geographic distance, but not ecological isolation, in shaping patterns of genetic variation 
in Peruvian Metallura tyrianthina. When $\mathrm{D}_{\mathrm{A}}$ was used as a metric for genetic distance, 33.9-85.3\% of the variance was explained by geographic isolation alone compared to the $0.9-40.3 \%$ attributable to certain climatic dissimilarities among localities. In no instance did climatic variation explain patterns of genetic variation better than geographic distance (Table 1). Moreover, the genetic variance explained by geographic distance alone was found to be significant when each of the different climatic models were accounted for using permutation tests. The highest level of genetic variance explained by climate was when $\mathrm{PC} 1$ of temperature, precipitation, and seasonality were all included in a model (40.3\%). This was also the only combination of climatic variables found to explain a significant proportion of the genetic variance using the permutation test; however, there was also a high degree of collinearity between geography and climate when all climate parameters were included in the model (shared proportion of variance: -0.386). Patterns for linearized Fst values were consistent with those found for $\mathrm{D}_{\mathrm{A}}$, in that geographic isolation always explained a greater proportion of the variance (10.07-31.60 \%) than climate (0.78-12.87 \%). However, less of the overall variance was explained by geographic isolation and, using the same permutation test, none of the variance explained by geographic distance was found to be significant when climate was accounted for (and vice versa).

A simple linear regression of bill length versus body mass indicated a weak, positive relationship $(p=0.015$; $\mathrm{R}^{2}=0.024$ ); however, body mass was also found to contribute very little to bill length variation in $M$. tyrianthina relative to climatic factors in an AICc analysis (Table 2). Given the weak relationship between body mass and bill length we use length measurements uncorrected for variation in body mass for all subsequent analyses. Divergence in mean bill length was greater in comparisons between habitats than comparisons within habitats (TukeyHSD test; $p<0.001$; Fig. 3). Bill length divergence was comparable among humid and semihumid population comparisons, respectively ( $p>0.1$; Fig. 3c). There were no relationships between genetic distance and

Table 2 The two best models predicting bill length variation based on AICc analysis: (1) seasonality, precipitation and their interaction; and (2) seasonality alone

\begin{tabular}{llllll}
\hline Model & $\log L$ & $\mathrm{k}$ & $\mathrm{AlCC}$ & $\Delta \mathrm{AICC}$ & Model weights \\
\hline [seas][prec][seas*prec] & -310.02 & 5 & 630.29 & 0 & 0.7776 \\
[seas] & -313.34 & 3 & 632.79 & 2.50 & 0.2224 \\
[mass] & -379.04 & 3 & 764.18 & 133.89 & 0
\end{tabular}

The 21 models we evaluated include all 15 possible combinations of body mass, PC1 of seasonality (seas), PC1 of precipitation (prec), PC1 of temperature (temp) as well as all six pairwise interactions among the four predictor variables. Relative variable importance (the sum of model weights in which a particular variable appears) was much greater for seasonality (1.0) than precipitation (0.55), temperature $(0.35)$, or body mass $(0.37)$ bill length divergence, regardless of whether we compared all populations, populations within the same habitat, or populations between habitats (for all $p>0.1$; Fig. 3).

The model including an interaction between PC1 of seasonality and $\mathrm{PC} 1$ of precipitation, plus their main effects, was the single best model explaining bill length variation, containing $77.8 \%$ of the Akaike weight. The second best model consisted solely of the PC1 of seasonality $(22.2 \%$ Akaike weight; $\triangle \mathrm{AICc}=2.50)$. Although a number of models were competitively ranked with $\mathrm{PC} 1$ of seasonality (i.e., $\triangle \mathrm{AICc}<2$ ) all of these models include $\mathrm{PC} 1$ of seasonality as a nested component and were thus considered uninformative (Table 2; [87]). We additionally quantified the relative importance of each predictor variable by adding together the model weights for each model in which the variable appeared [93]. This analysis highlighted the overwhelming influence of seasonality (1.0) relative to precipitation (0.55), temperature $(0.35)$, or body mass (0.37). Linear regression of bill length versus PC1 of seasonality was also highly significant $(p<0.0001$; $R^{2}=0.44$; Fig. 4). Seasonality remained a significant explanatory variable of bill length variation after accounting for spatial autocorrelation by incorporating data on latitude and longitude from each sampling site into a nonlinear mixed effects model in the R package nlme (https:// cran.r-project.org/web/packages/nlme/index.html).

\section{Dual influence of topography on divergence}

ND2, AK1 and MUSK all exhibited significant divergence in Fst across the Cordillera de Vilcanota between Urubamba and Carrizales, Fst for Bfib7 was non-significant (Table 3). Significant Fst structure along the Manu Road was only found for the $A K 1$ intron, which also had a lower Fst value (0.184) than across the Cordillera de Vilcanota (0.336). Significant genetic structure was also found between the two humid sites (Carrizales and Pillahuata) across all loci and for $N D 2$ and $A K 1$ between the two drier sites (Urubamba and Paucartambo).

IMa2 analyses of populations separated by the Cordillera de Vilcanota and between the two semi-humid sampling localities showed good evidence of convergence with ESS values $>150$ and all three runs exhibiting similar values for all parameters. By contrast, analyses of the populations along the Manu Road and comparisons between the two humid-site populations did not exhibit evidence for convergence (ESS values $<100$ ) after sampling 250,000 genealogies despite similar results being obtained across each of the three independent runs. Migration rates $(m)$ based on all four loci across both humid to semi-humid comparisons were found to be greater than zero (Fig. 5a; Table 4); however, average migration rates along the Manu Road (39.92; 95 \% HPD: 6.31-150) were estimated to be over 19 times greater than the average migration rate across the Cordillera de Vilcanota (2.10; 95 \% HPD: 0.38-9.76). 


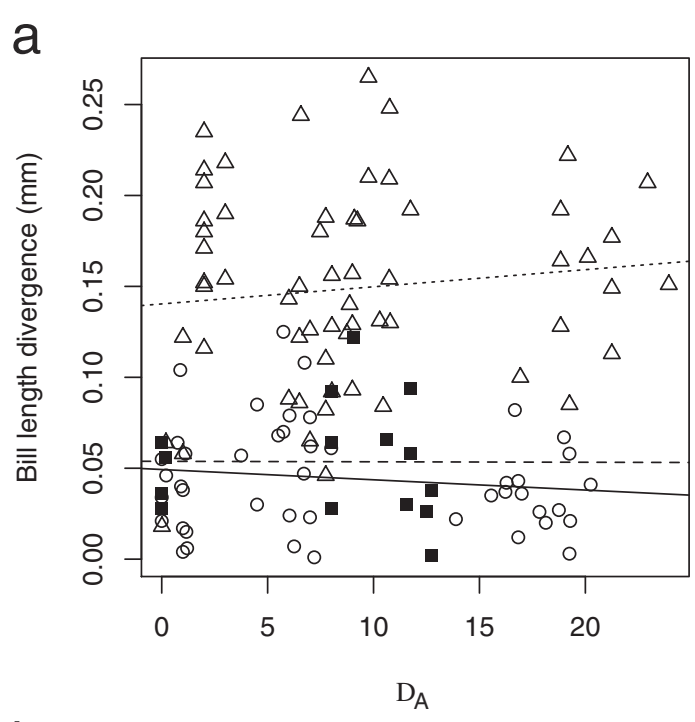

b

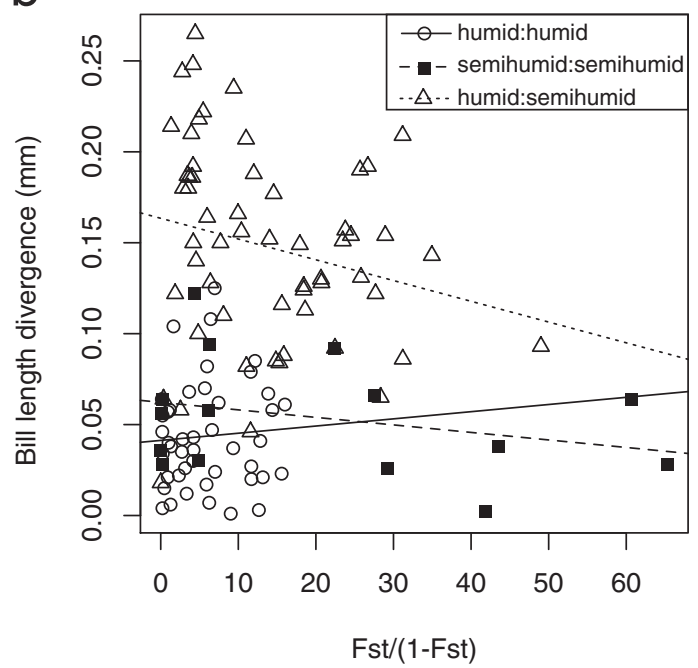

C

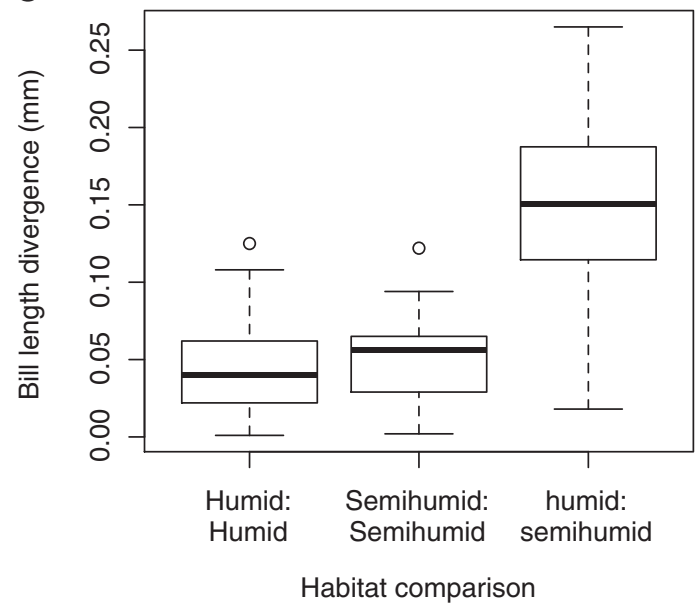

Fig. 3 Linear regression of bill length versus a pairwise genetic differences $\left(D_{A}\right)$ and $\mathbf{b}$ linearized Fst among all populations. No significant relationships were found across all comparisons. c Boxplot of mean divergence in bill length between all humid sites, semi-humid sites, and among sites in different habitats. Mean divergence between habitats was significantly greater than that between habitats, whereas within habitat divergence did not differ

Within habitat migration rates were greater on average between the two humid sites (39.70; 95 \% HPD: 1.51100) than between the two semi-humid sites (3.38; 95 \% HPD: 0.68-36.50). Estimated average divergence times were greater between the Urubamba population and all others $(0.74-0.94 \mathrm{Ma})$ than they were between the two Manu Road populations $(0.03 \mathrm{Ma})$ or between the two humid-climate populations (0.03 Ma; Table 4). However, the $95 \%$ HPDs of all divergence time estimates overlapped and resolution of this parameter was generally poor, with a peak found in the distribution of $t$ followed by either a long plateau or the values of $t$ decreasing in probability but plateauing at a low nonzero value. The poor resolution of dates was most likely due to insufficient data. $\theta$ was generally low, varying from 0.14 to 1.40 in all well-resolved populations (Table 4). The posterior distribution of $\theta_{\mathrm{A}}$ was always poorly resolved as was $\theta$ for the population sampled at Pillahuata with estimates exhibiting long non-zero tails within the specified prior distribution. Again, we think that this is due to insufficient data to resolve these estimates rather than an inappropriate designation of the upper bound of the prior given that all other population sizes were much smaller than the upper bound (see above).

Cusco populations on the drier, west-facing slopes had longer bills than those on the humid, east-facing slopes (Fig. 5b). Bill length in Urubamba was significantly longer than all three of the other populations $(p<0.0001)$. Although bill length in Paucartambo was slightly longer (average $0.47 \mathrm{~mm}$ ) than birds from the adjacent humid slopes at Pillahuata, this result was not significant when corrected for multiple comparisons $(p=0.216)$. There were no differences in bill length between the two humid sites $(p>0.4)$.

\section{Discussion}

\section{Geographic isolation promotes genetic divergence}

Phylogenetic, network, and AMOVA analyses all point to an important role for topographic barriers in structuring genetic diversity in Metallura tyrianthina, a result consistent with studies of the Genus Metallura as a whole [51, 94] and many other Andean taxa (e.g. [9, 21, 40, 95-97]). We found the North Peru Low, Apurímac Valley and high Andean ridges to be associated with genetic structure in $M$. tyrianthina as in many other taxa [20, 97, 98]. We also found the Cordillera de Vilcanota to be an important 


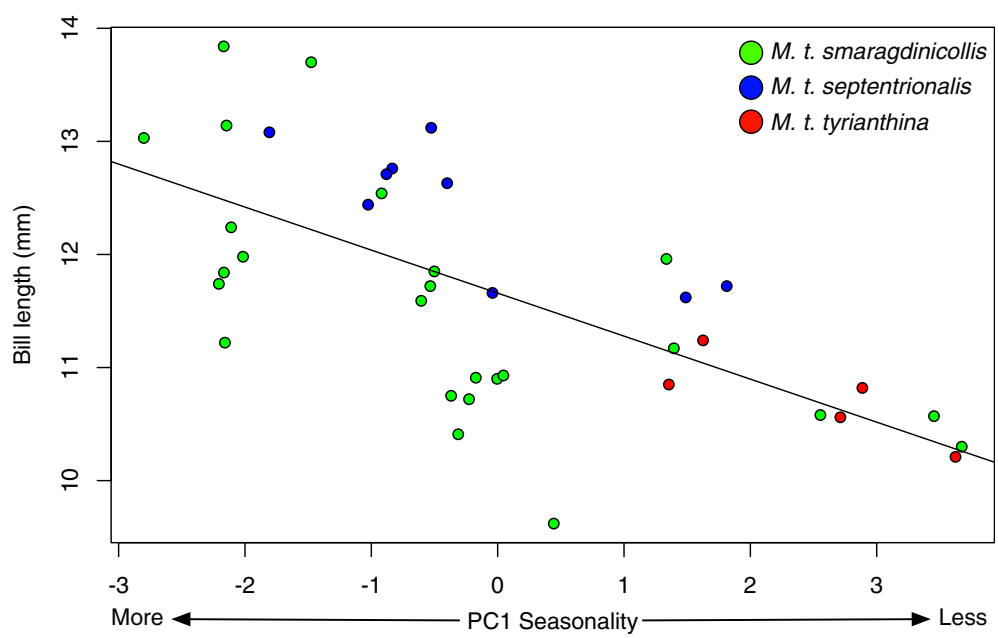

Fig. 4 Bill length as a function of PC1 of seasonality ( $82.9 \%$ of the variation). The linear regression model was highly significant $(p<0.0001)$ with an $R^{2}$ of 0.44

landscape feature structuring genetic and phenotypic diversity; the same cordillera was linked to an older phenotypic and genetic divergence in the hummingbird Adelomyia melanogenys [65]. Topographic barriers were implicated in generating neutral genetic divergence, but not divergence in bill length (Fig. 3; [22]). This suggests that hummingbird bill morphology does not evolve steadily over time, but diverges only in response to differential ecological pressures.

Although we found discordant patterns of genetic and morphological divergence in M. tyrianthina, patterns of plumage variation in the species appear to vary in association with topographic barriers and the degree of genetic divergence. A high Andean ridge separates the similar looking subspecies $M$. t. smaragdinicollis and $M$. t. septentrionalis, and the Marañón valley corresponds to turnover between the red-tailed subspecies, $M . t$. tyrianthina, and the two purple-tailed subspecies occupying the rest of Peru [48]. Plumage variation among these subspecies cannot be explained by the climatic characteristics of the regions in which they are distributed. Instead, plumage divergence generally corresponds with time since divergence. The two similar purple-tailed

Table 3 Fst-values among pairwise comparisons of all four Cusco localities (Fig. 1b)

\begin{tabular}{lllll}
\hline & Vilcanota & Manu Road & Humid & Semi-humid \\
\hline ND2 & $0.802^{* * *}$ & $-0.051^{\text {ns }}$ & $0.167^{*}$ & $0.814^{* * *}$ \\
AK1 & $0.336^{* *}$ & $0.184^{*}$ & $0.290^{* * *}$ & $0.245^{* * *}$ \\
Bfib7 & $-0.055^{\text {ns }}$ & $-0.0387^{\text {ns }}$ & $0.281^{*}$ & $-0.012^{\text {ns }}$ \\
MUSK & $0.368^{* * *}$ & $-0.055^{\text {ns }}$ & $0.229^{*}$ & $-0.069^{\text {ns }}$ \\
\hline
\end{tabular}

Vilcanota and Manu Road columns each represent a comparison between a pair of humid and semi-humid environments. Humid comparisons are between Carrizales and Pillahuata populations, semi-humid comparisons are between Urubamba and Paucartambo populations

${ }^{\mathrm{ns}} p>0.05 ;{ }^{*} p<0.05 ;{ }^{* *} p<0.01 ;{ }^{* * *} p<0.001$ subspecies, which occupy different environments, were found to be only $0.24 \%$ divergent at the ND2 locus; whereas divergence between red and purple-tailed subspecies distributed in similar environments across the Marañón valley was $\sim 2.2 \%$. Concordance between tail color and genetic divergence in M. tyrianthina is consistent with the positive correlation between the extent of plumage and mtDNA divergence across the Marañón valley, based on multiple passerine genera [22]. Plumage divergence rate appears to be linked to neutral genetic divergence and decoupled from functional trait divergence (but see [28]).

\section{Bill length varies in association with climate}

Populations of Metallura tyrianthina occupying habitats characterized by semi-humid montane scrub were found to have significantly longer bills than birds in humid forest habitats (Fig. 3c). This marked morphological divergence was not associated with neutral genetic divergence; rather, we found a strong relationship between climatic and bill length variation, with a model of seasonality, precipitation and their interaction being the strongest predictor of bill variation (Table 1) and seasonality being the most important single predictor (Fig. 4). Our estimate of the strength of this relationship $\left(r^{2}=0.44\right)$ is likely conservative considering that the climate data is coarsely interpolated from unevenly distributed weather stations in the Peruvian Andes. In the Andes, consistent patterns of morphological divergence occurring in association with ecological dissimilarities have been found in Adelomyia hummingbirds [26, 65] and Glyphorhynchus woodcreepers [32, 64]. A similar relationship between bill length and climate was found in the hummingbird Adelomyia melanogenys, where $57 \%$ of the variance in bill length was explained by precipitation seasonality, minimum temperature of the 

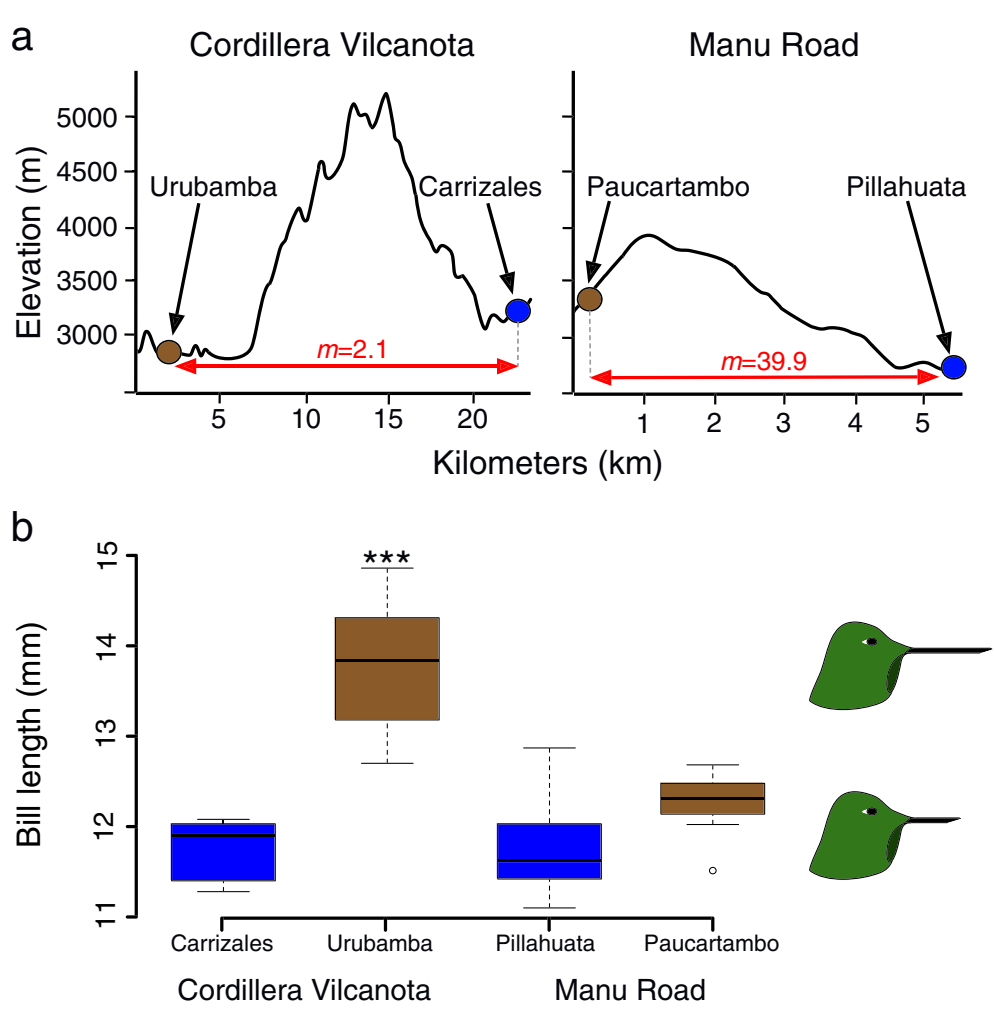

Fig. 5 a Topographic profiles of the two cordilleras separating sampling sites in the Vilcanota region and along the Manu Road (see Fig. 1c). Arrows with red lettering indicate mean migration rates $(m)$ estimated from IMa2 analyses (Table 4). b Bill length differences among the four Cusco localities. Blue represents the two humid sites and brown the two drier sites. Asterisks indicate p-values for the comparisons of bill length between two pairs of adjacent populations in humid and semi-humid environments $\left({ }^{*}<0.05\right.$; $^{* *}<0.001$; $\left.{ }^{* *}<0.0001\right)$

coldest month, and mean elevation [65]. These results suggest that climatic variables or other ecological factors correlated with climate (see below) may play important roles in shaping the impressive diversity of hummingbird bill morphology in the Andes. Concordance between ecological variation and morphological variation is well documented in organisms [99] especially birds where bill morphology responds readily to climatic and dietary change [100-102]. Patterns of bill morphology in $M$. tyrianthina contribute to mounting evidence that the ecological differences generated by the topographically complex Andean landscape play an important role in promoting local adaptation and functional diversity in Andean taxa [28, 30, 32, 33, 65].

The variation partitioning approach we used to test for IBE revealed that geographic distance, not climatic variation, explained the greatest proportion of genetic variance. These results provide additional evidence for an exclusive role of geographic isolation in promoting genetic divergence at the neutral loci studied. Our results resemble a similar study in Trinidadian guppies where no influence of ecological dissimilarity on genetic variation was detected [103]. However, both a study of Caribbean Anolis species [80] and a meta-analysis [79] found consistent roles for

Table 4 Parameter estimates for $\theta\left(4 \mathrm{~N}_{e} \mu\right)$, divergence time $(t)$, and symmetrical migration rates $(m)$ inferred from IMa2 analyses

\begin{tabular}{llllll}
\hline Transect & $\theta_{1}$ & $\theta_{2}$ & $\theta_{\text {ancestral }}$ & $t$ & $m$ \\
\hline Vilcanota & $0.321(0.103-0.903)$ & $0.807(0.205-3.117)$ & $0.06(0.00-4.00)$ & $0.7985(0.295-3.0)$ & $2.098(0.383-9.759)$ \\
Manu Road & $1.402(0.027-0.379)$ & $4.00(0.140-4.00)$ & $1.521(0.00-4.00)$ & $0.031(0.016-2.998)$ & $39.922(6.308-150)$ \\
Humid & $6.000(0.042-6.0)$ & $0.140(0.036-0.499)$ & $0.587(0-6.00)$ & $0.026(0.001-2.998)$ & $39.702(1.513-100)$ \\
Semi-humid & $0.260(0.062-0.973)$ & $0.77(0.039-1.199)$ & $1.746(0.0-4.00)$ & $0.939(0.052-2.998)$ & $3.379(0.676-36.501)$ \\
\hline
\end{tabular}

$95 \%$ HPD range for each parameter presented in parentheses. Mean parameter estimates represent the average across the three independent runs performed for all four comparisons. $\theta_{1}$ refers to estimates of $\theta$ for the semi-humid comparison for Vilcanota and Manu Road and $\theta_{2}$ for the humid site. For between humid sites and semi-humid site comparisons $\theta_{1}$ refers to sites from the Manu Road and $\theta_{2}$ the Vilcanota 
ecologically mediated genetic divergence when comparing the influence of geographic and ecological distance on patterns of genetic variation. In the Andes, similar analyses assaying genetic variation among populations of the woodcreeper Glyphorynchus spirurus in Ecuador found that the Andean ridge separating eastern and western populations played the largest role in structuring genetic divergence. Whereas genetic variance within eastern or western populations was explained largely by ecological variation [64]. Although we do not find evidence for isolation by environment in M. tyrianthina, negative results for this test can be difficult to interpret due to factors such as insufficient time for divergence to occur at neutral loci or inappropriate ecological variables selected [18]. Other distance estimates, such as resistance-based distances [104], consistently explain a greater proportion of the variance in genetic diversity than Euclidean geographic distance [80]. Thus, our use of Euclidean distances likely resulted in a conservative estimate of the effect of geographic features on genetic divergence. In general, the results of our variation partitioning and phylogeographic analyses implicate geographic isolation as the major driver of neutral genetic divergence in this species, with little or no additional divergence attributable to ecological differences.

\section{Barriers facilitate functional divergence}

In a wide array of taxa, mismatches between morphology and neutral genetic diversity have been interpreted as evidence for phenotypic divergence with gene flow $[26,32,105-108]$. These studies have generally compared morphology of adjacent populations in different environments versus isolated populations in similar environments; however, they do not assess the extent to which gene flow might prevent populations from achieving local adaptive optima. We compared patterns of gene flow and morphological divergence between pairs of populations in humid and semi-humid environments that were either isolated by a topographic barrier (Cordillera de Vilcanota) or not (Manu Road; Fig. 5a). This allowed us to assess how interactions between barriers and climate might facilitate functional diversification. At all four loci, we found greater Fst-values across the Cordillera de Vilcanota than the Manu Road, with only a single locus exhibiting an Fst significantly different from zero along the Manu Road (Table 3). Coalescent-based analyses in IMa2 confirmed that migration rates across the Manu Road were significantly greater than across the Cordillera de Vilcanota (Fig. 5a; Table 4). Furthermore, migration rates along the Manu Road were found to be equal to or greater than rates between the two humid sites or between the two semi-humid sites. Although MCMC searches in some IMa2 analyses exhibited uncertain convergence, three independent runs always indicated higher migration rates along the Manu Road than across the
Vilcanota, and Fst values corroborated patterns suggested by IMa2 analysis.

We found an inverse relationship between bill length divergence and gene flow, with greater divergence in bill length found across the Cordillera de Vilcanota than the Manu Road (Fig. 5b). A similar relationship between gene flow and adaptive divergence has been found in numerous non-Andean taxa $[17,36-38,109]$. Although this pattern has frequently been interpreted as the result of gene flow constraining adaptive divergence, adaptive divergence could also restrict gene flow to the extent that it reinforces reproductive isolation. Teasing apart these mechanisms is a widely recognized challenge $[17,110]$. In the present case, the fact that landscape features appear to explain levels of gene flow (Fig. 5a) suggests that adaptive divergence is constrained by gene flow, rather than the reverse.

An alternative explanation for differences in bill length between Urubamba and Paucartambo is that they reflect differences in the amount of time spent in semi-humid environments. In support of this possibility, migration-rate estimates from IMa2 can be spuriously high, according to two recent simulation studies [111, 112]. Both studies found that in cases of recent divergence (i.e. low Fst), datasets with few loci exhibited high false-positive rates for non-zero migration. Given that we only sequenced four unlinked loci, it is possible that this bias could have conflated the migration rates that we found along the Manu Road. However, we think it is likely that low Fst between populations distributed along the Manu Road was due, at least in part, to ongoing gene flow. These populations are only $5 \mathrm{~km}$ apart and the intervening area contains a gradual habitat transition from semi-humid scrub to humid forest. Secondly, the uplift of the Cordillera dividing the two sampled populations along the Manu Road occurred $>4$ Ma before $M$. tyrianthina colonized the central Andes from the north [45, 51, 113]. Although we consider high gene flow to be the most likely interpretation of low genetic divergence across the Manu Road, our relative estimates of gene flow and divergence time should be interpreted with caution. The most conservative interpretation of our results is that bill length similarity is associated with genetic similarity at the population level, regardless of whether that similarity is due to recent divergence or ongoing connectivity.

Although subtle morphological divergence in the face of gene flow has been demonstrated in other Andean birds (e.g. Glyphorynchus spirurus [32]), phylogenetic analyses have failed to find a pattern of sister species replacement along ecological gradients [42, 43, 51]. Our results potentially reconcile these contradictory patterns as we find that adaptive divergence with gene flow is possible, but severely constrained. In Andean birds, it appears that allopatry is a pre-requisite or co-requisite for functional diversification and likely the completion of speciation. 


\section{Selection for longer bills}

Repeated evolution of longer bills in drier, more seasonal habitats suggests adaptation by natural selection, although the mechanism by which increased bill length may increase fitness in these environments has yet to be tested. Given that climatic variation likely covaries with a number of other potential ecological pressures, pinpointing the mechanistic basis of inter-population variation in bill length would require rigorous field observations and experimentation. Climate could play a direct role in driving bill length differences; however, bill length variation in M. tyrianthina and other Metallura species [114] directly contradicts Allen's Rule [100]. Additionally, even though increased bill size can be a key mechanism for shedding excess heat while conserving water in drier environments $[102,115,116]$ hummingbirds acquire large volumes of water from their nectarivorous diets and as a consequence do not suffer from water limitations to the same degree as other birds [117]. Instead, biotic interactions represent more likely drivers of geographic variation in bill length in Metallura tyrianthina. First, longer bills in drier, less diverse environments could be caused by competitive release, analogous to bird populations on depauperate islands which tend to exhibit divergent bill morphologies as part of a more generalist phenotype [118-120]. M. tyrianthina has a shorter bill than most other hummingbird species in the humid forests of east-facing Andean slopes. Longer bills might allow $M$. tyrianthina to exploit a greater variety of flowers on rain-shadowed slopes that harbor fewer competing nectarivore species. Second, diversifying selection on bill length could be exerted by flower species that have different corolla shapes, a coevolutionary process that has been well-documented in other hummingbird species [55-57, 121]; this is plausible for $M$. tyrianthina because striking floral species turnover coincides with the climatic gradients along which it occurs.

\section{Conclusions}

Andean ridges and valleys hinder connectivity among populations and also create local climatic variation that imposes differential selection pressures $[10,46]$. We investigated this dual role of topography for its effects on diversity in a widespread hummingbird species, Metallura tyrianthina. Across the Peruvian distribution of this species, we found that topographic barriers play the dominant role in structuring effectively neutral genetic diversity, whereas climatic variation shapes patterns of bill morphology. Moreover, analyses across four sites in the department of Cusco indicated that topography promotes genetic structure even across small spatial scales $(<20 \mathrm{~km})$ and bills are longer on rainshadowed, west-facing slopes. This fine-scale analysis also revealed how gene flow constrains functional divergence, suggesting that topography and climatic variation interact to promote Andean diversification. If functional divergence driven by climatic variation permits coexistence upon secondary contact [19], it could potentially contribute to the evolution of reproductive isolation at later stages of divergence [18]. These processes could increase the overall tempo of diversification [122, 123]. Based on our results from Metallura, the east-to-west precipitation gradient may have played an important role in the diversification of several avian genera that contain narrowly distributed and geographically variable taxa in the central Andes (e.g. Ochthoeca, Anairetes, Atlapetes, Cranioleuca, Spinus). Indeed, analyses comparing speciation rates among Andean and adjacent lowland lineages have found overall higher speciation rates in the Andes, a pattern driven in part by genera such as Cranioleuca [124, 125] and Spinus $[125,126]$. Topographic barriers and ecological variation have clearly interacted to produce high species diversification rates in Andean birds. The current results suggest that rates of functional diversification should also be accelerated when physical landscape features coincide with ecoclimatic variation.

\section{Availability of supporting data}

The bill length dataset supporting the results of this article are included within the article (and its additional file(s)). Mitochondrial and nuclear intron sequence data have been deposited on GenBank, accession numbers: KU527140-KU527416.

\section{Additional file}

Additional file 1: Table S1. Museum specimens and tissues used in study, sampling localities, bill length measurements, and body mass. Table S2. Loadings from principal component analysis of temperature, precipitation, and seasonality Bioclim variables. Table S3. Loadings from principal components analysis of all 19 BioClim variables. Table S4. Parameter settings for each of the four IMa2 analyses. Table S5. Corrected pairwise differences and Fst values among all populations. Table S6. Results of AMOVA analysis. Table S7. Standard indices of molecular diversity for each clade based on ND2. (DOCX $174 \mathrm{~kb})$

Competing interests

The authors declare that they have no competing interests.

Authors' contributions

PMB and CCW designed the research and wrote the paper. P.M.B. collected and analyzed the data. Both authors have read and approved the final version of the manuscript.

\section{Acknowledgements}

We thank the following museums and individuals for providing access to tissues and specimens: Centro de Ornitologia y Biodiversidad (CORBIDI: T. Valqui, W. Nuñez); Lousiana State University Museum of Natural Science (LSUMZ: D. Dittmann, R. T. Brumfield); Field Museum of Natural History (FMNH: D. Willard); the Museum of Southwestern Biology of the University of New Mexico (MSB: A.B. Johnson). Labwork, fieldwork, and logistics were only possible with the help of R.W. Dickerman, E. J. Beckman, S. G. DuBay, N. A. Wright, L. M. Flores, A. Quiñonez Z., E. Bautista, S. Figueroa, S. M. McNew, C. J. Schmitt, A. B. Johnson, M. J. Lelevier, M. R. Jones, T. Valqui, and personnel at 
DGFFS (now SERFOR) in Peru. This work was funded in part by the following grants: F. M. Chapman Memorial Fund of the AMNH, UNM Biology Department Scholarships, NSF grant DEB-1146491, and a seed grant from the UNM Center of Evolutionary and Theoretical Immunology.

\section{Received: 16 October 2015 Accepted: 18 January 2016}

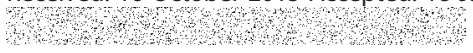

\section{References}

1. Myers N, Mittermeier RA, Mittermeier CG, da Fonesca GAB, Kent J. Biodiversity hotspots for conservation priorities. Nature. 2000;403:853-8.

2. Price TD, Hooper DM, Buchanan CD, Johansson US, Tietze DT, Alström P, et al. Niche filling slows the diversification of Himalayan songbirds. Nature. 2014;509:222-5

3. Hall JPW. Montane speciation patterns in Ithomiola butterflies (Lepidoptera: Riodinidae): are they consistently moving up in the world? Proc Roy Soc Lond B. 2005;272:2457-66.

4. Roberts $J$, Brown JL, May RV. Genetic divergence and speciation in lowland and montane Peruvian poison frogs. Mol Phylogenet Evol. 2006:41:149-64.

5. McGuire JA, Witt CC, Altshuler DL, Remsen Jr JV. Phylogenetic systematics and biogeography of hummingbirds: Bayesian and maximum likelihood analyses of partitioned data and selection of an appropriate partitioning strategy. Syst Biol. 2007:56:837-56.

6. Elias M, Joron M, Willmott K, Silva-Brandão KL, Kaiser $V$, Arias CF, et al. Out of the Andes: patterns of diversification in clearwing butterflies. Mol Ecol. 2009; 18:1716-29.

7. Sedano RE, Burns KJ. Are the northern Andes a species pump for Neotropical birds? Phylogenetics and biogeography of a clade of Neotropical tanagers (Aves: Thraupini). J Biogeogr. 2010;37:325-43.

8. Hutter CR, Guayasamin JM, Wiens JJ. Explaining Andean megadiversity: the evolutionary and ecological causes of glassfrog elevational richness patterns. Ecol Lett. 2013;16:1135-44.

9. Pocco ME, Posadas P, Lange CE, Cigliano MM. Patterns of diversification in the high Andean Ponderacris grasshoppers (Orthoptera: Acrididae: Melanoplinae) Syst Entomol. 2013;38:365-89.

10. Ruggiero A, Hawkins BA. Why do mountains support so many species of birds? Ecography. 2008;31:306-15.

11. Jordan DS. The origin of species through isolation. Science. 1905;22:545-62.

12. Mayr E. Systematics and the origin of species. New York: Columbia University Press; 1942.

13. Mayr E. Animal species and evolution. Cambridge: Belknap Press of Harvard University Press; 1963.

14. Graves GR. Elevational correlates of speciation and intraspecific geographic variation in Andean forest birds. Auk. 1985;103:556-79.

15. Price TD. Speciation in Birds. Greenwood Village: Roberts \& Company; 2008.

16. Via S. Sympatric speciation in animals: the ugly duckling grows up. Trends Ecol Evol. 2001;16:381-90.

17. Räsänen K, Hendry AP. Disentangling interactions between adaptive divergence and gene flow when ecology drives diversification. Ecol Lett. 2008:11:624-36

18. Nosil P. Ecological Speciation. Oxford: Oxford University Press; 2012.

19. Price TD. The roles of time and ecology in the continental radiation of the Old World leaf warblers (Phylloscopus and Seicercus). Philos T Roy Soc B. 2010;365:1749-62

20. Cracraft J. Historical biogeography and patterns of differentiation within the South American avifauna: areas of endemism. Ornithol Monogr. 1985;36:49-84.

21. Picard D, Sempere T, Plantard O. Direction and timing of uplift propagation in the Peruvian Andes deduced from molecular phylogenetics of highland biotaxa. Earth Planet Sc Lett. 2008;271:326-36.

22. Winger $\mathrm{BM}$, Bates JM. The tempo of trait divergence in geographic isolation: avian speciation across the Marañon Valley of Peru. Evolution. 2015;69:772-82.

23. Coyne JA, Orr HA. Speciation. Sunderland: Sinauer Associates, Inc.; 2004.

24. Hedges SB, Marin J, Suleski M, Paymer M, Kumar S. Tree of life reveals clock-like speciation and diversification. Mol Biol Evol. 2015;32:835-45.

25. Cadena CD, Klicka J, Ricklefs RE. Evolutionary differentiation in the Neotropical montane region: molecular phylogenetics and phylogeography of Buarremon brush- finches (Aves, Emberizidae). Mol Phylogenet Evol. 2007:44: 993-1016.

26. Chaves JA, Pollinger JP, Smith TB, LeBuhn G. The role of geography and ecology in shaping the phylogeography of the speckled hummingbird (Adelomyia melanogenys) in Ecuador. Mol Phylogenet Evol. 2007;43:795-807.
27. Weir JT, Bermingham E, Miller MJ, Klicka J, González MA. Phylogeography of a morphologically diverse Neotropical montane species, the common bush-tanager (Chlorospingus opthalmicus). Mol Phylogenet Evol. 2008;47: 650-64.

28. Cadena CD, Cheviron ZA, Funk WC. Testing the molecular and evolutionary causes of a 'leapfrog' pattern of geographical variation in coloration. J Evolution Biol. 2011;24:402-14.

29. Kozak KH, Wiens JJ. Accelerated rates of climatic-niche evolution underlie rapid species diversification. Ecol Lett. 2010;13:1378-89.

30. Cheviron ZA, Brumfield RT. Migration-selection balance and local adaptation of mitochondrial haplotypes in rufous-collared sparrows (Zonotrichia capensis) along an elevational gradient. Evolution. 2009;63:1593-605.

31. McCracken KG, Barger CP, Bulgarella M, Johnson KP, Kuhner MK, Moore AV, et al. Signatures of high-altitude adaptation in the major hemoglobin of five species of Andean dabbling ducks. Am Nat. 2009:174:631-50.

32. Milá B, Wayne RK, Fitze P, Smith TB. Divergence with gene flow and finescale phylogeographical structure in the wedge-billed woodcreeper, Glyphorynchus spirurus, a Neotropical rainforest bird. Mol Ecol. 2009;18: 2979-95.

33. Wilson RE, Peters JL, McCracken KG. Genetic and phenotypic divergence between low- and high-altitude populations of two recently diverged cinnamon teal subspecies. Evolution. 2012;67:170-84.

34. Gutiérrez-Pinto N, McCracken KG, Alza L, Tubaro P, Kopuchian C, Astie A, et al. The validity of ecogeographic rules is context dependent: testing for Bergmann's and Allen's rules by latitude and elevation in a widespread Andean duck. Biol J Linn Soc. 2014:111:850-62.

35. Galen SC, Natarajan C, Moriyama H, Weber RE, Fago A, Benham PM, et al. Contribution of a mutational hotspot to hemoglobin adaptation in highaltitude Andean house wrens. Proc Nat Acad Sci USA. 2015. doi:10.1073/ pnas. 1507300112.

36. Nosil P, Crespi BJ. Does gene flow constrain adaptive divergence or vice versa? A test using ecomorphology and sexual isolation in Timema cristinae walking-sticks. Evolution. 2004;58:102-12.

37. Postma E, van Noordwijk AJ. Gene flow maintains a large genetic difference in clutch size at a small spatial scale. Nature. 2005;433:65-8.

38. Nosil P. Ernst Mayr and the integration of geographic and ecological factors in speciation. Biol J Linn Soc. 2008;95:26-46.

39. Graham CH, Ron SR, Santos JC, Schneider CJ, Moritz C. Integrating phylogenetics and environmental niche models to explore speciation mechanisms in dendrobatid frogs. Evolution. 2004:58:1781-93.

40. Patton $J$, Smith MF. mtDNA phylogeny of Andean mice: a test of diversification of across ecological gradients. Evolution. 1992;46:174-83.

41. Ribas CC, Moyle RG, Miyaki CY, Cracraft J. The assembly of montane biotas: linking Andean tectonics and climatic oscillations to independent regimes of diversification in Pionus parrots. Proc Roy Soc Lond B. 2007:274:2399-408.

42. Parra JL, Remsen Jr JV, Alvarez-Reballedo M, McGuire JA. Molecular phylogenetics of the hummingbird genus Coeligena. Mol Phylogenet Evol. 2009;53:425-34

43. Quintero E, Ribas CC, Cracraft J. The Andean Hapalopsittaca parrots (Psittacidae, Aves): an example of montane-tropical lowland vicariance. Zool Scr. 2013;42: 28-43.

44. Freeman BG. Competitive interactions upon secondary contact drive elevational divergence in tropical birds. Am Nat. 2015:186:470-9.

45. Schluter D. Evidence for ecological speciation and its alternative. Science. 2009;323:737-41.

46. Graves GR. Bergmann's rule near the equator: latitudinal clines in body size of an Andean passerine bird. Proc Nat Acad Sci USA. 1991;88:2322-5.

47. Gregory-Wodzicki KM. Uplift history of the central and northern Andes: a review. Geol Soc Am Bull. 2000;112:1091-105.

48. Schulenberg TS, Stotz DS, Lane DF, O'Neill JP, Parker III TA. Birds of Peru. Princeton: Princeton University Press; 2007.

49. Hoorn C, Isselingh FP, ter Steege H, Bermudz MA, Mora A, Sevink J, et al. Amazonia through time: Andean uplift, climate change, landscape evolution, and biodiversity. Science. 2010;330:927-31.

50. Rech JA, Currie BS, Shullenberger ED, Dunagan SP, Jordan TE, Blanco N, et al. Evidence for the development of the Andean rain shadow from a Neogene isotopic record in the Atacama Desert. Chile Earth Planet Sc Lett. 2010;292:371-82

51. Benham PM, Cuervo AM, McGuire JA, Witt CC. Biogeography of the Andean metaltail hummingbirds: contrasting evolutionary histories of tree line and habitat-generalist clades. J Biogeogr. 2015;42:763-77. 
52. Edgar RC. MUSCLE: multiple sequence alignment with high accuracy and high throughput. Nucleic Acids Res. 2004;32:1792-7.

53. Stephens M, Smith NJ, Donnely P. A new statistical method for haplotype reconstruction from population data. Am J Hum Genet. 2001;68:978-89.

54. Stephens M, Donnely P. A comparison of Bayesian methods for haplotype reconstruction. Am J Hum Genet. 2003:73:1162-9.

55. Temeles EJ, Koulouris CR, Sander SE, Kress WJ. Effect of flower shape and size on foraging performance and trade-offs in a tropical hummingbird. Ecology. 2009;90:1147-61.

56. Nattero J, Sérsic AN, Cocucci AA. Geographic variation of floral traits in Nicotiana glauca: relationships with biotic and abiotic factors. Acta Oecol. 2010;37:503-11.

57. Temeles EJ, Kress WJ. Adaptation in a plant-hummingbird association. Science. 2003;300:630-3.

58. Grant PR, Price TD. Population variation in continuously varying traits as an ecological genetics problem. Amer Zool. 1981;21:795-811.

59. Winker K. Specimen Shrinkage in Tennessee Warblers and "Traill's" Flycatchers. J Field Ornithol. 1993;64:331-6.

60. Bleiweiss R. Joint effects of feeding and breeding behavior on trophic dimorphism in hummingbirds. Proc Roy Soc Lond B. 1999;266:2491-7.

61. Temeles EJ, Miller JS, Rifkin JL. Evolution of sexual dimorphism in bill size and shape of hermit hummingbirds (Phaethornithinae): a role for ecological causation. Philos T Roy Soc B. 2010;365:1053-63.

62. Hijmans RJ, Cameron SE, Parra JL, Jones PG, Jarvis A. Very high resolution interpolated climate surfaces for global land areas. Int J Climatol. 2005;25: 1965-78.

63. Graham $\mathrm{CH}$, Silva N, Velásquez-Tibatá J. Evaluating the potential causes of range limits of birds of the Colombian Andes. J Biogeogr. 2010;37:1863-75.

64. Thomassen HA, Buermann W, Milá B. Modeling environmentally associated morphological and genetic variation in a rainforest bird, and its application to conservation prioritization. Evol Appl. 2010;3:1-16.

65. Chaves JA, Smith TB. Evolutionary patterns of diversification in the Andean hummingbird genus Adelomyia. Mol Phylogenet Evol. 2011;60:207-18.

66. Tinoco BA, Astudillo PX, Latta SC, Graham CH. Distribution, ecology and conservation of an endangered Andean hummingbird: the violet-throated metaltail (Metallura baroni). Bird Conserv Int. 2009:19:63-76.

67. Ronquist F, Huelsenbeck JP. MRBAYES 3: Bayesian phylogenetic inference under mixed models. Bioinformatics. 2003;19:1572-4.

68. Miller MA, Pfeiffer W, Schwartz T. Creating the CIPRES science gateway for inference of large phylogenetic trees. Proceedings of the Gateway Computing Environments Workshop (GCE). 2010;1-8.

69. Akaike $\mathrm{H}$. A new look at the statistical model identification. IEEE T Automat Contr. 1974:19:716-23.

70. Posada D. jModelTest: Phylogenetic model averaging. Mol Biol Evol. 2008;25: 1253-6.

71. Guindon S, Gascuel O. A simple, fast, and accurate method to estimate large phylogenies by Maximum Likelihood. Syst Biol. 2003;52:696-704.

72. Nylander JAA, Wilgenbusch JC, Warren DL, Swofford DL. AWTY (are we there yet?): a system for graphical exploration MCMC convergence in Bayesian phylogenetics. Bioinformatics. 2008;24:581-3.

73. Librado P, Roza J. DnaSP v5: a software for comprehensive analysis of DNA polymorphism data. Bioinformatics. 2009;25:1451-2.

74. Bandelt HJ, Forster $P$, Rohl A. Median-joining networks for inferring intraspecific phylogenies. Mol Biol Evol. 1999;16:37-48.

75. Weir JT. Implications of genetic differentiation in Neotropical montane forest birds. Ann Mo Bot Gard. 2009;96:410-33.

76. Nei M, Li WH. Mathematical model for studying genetic variation in terms of restriction endonucleases. Proc Nat Acad Sci USA. 1979;76:5269-73.

77. Excoffier L, Laval G, Schneider S. Arlequin ver. 3.0: An integrated software package for population genetics data analysis. Evol Bioinformatics Online. 2005;1:47-50.

78. Slatkin M. Inbreeding coefficients and coalescence times. Genet Res. 1991; 58:167-75.

79. Shafer ABA, Wolf JBW. Widespread evidence for incipient ecological speciation: a meta- analysis of isolation-by-ecology. Ecol Lett. 2013;16:940-50.

80. Wang IJ, Glor RE, Losos JB. Quantifying the roles of ecology and geography in spatial genetic divergence. Ecol Lett. 2012;16:175-82.

81. Wang IJ, Bradburd GS. Isolation by environment. Mol Ecol. 2014;23:5649-62.

82. Oksanen J, Kindt R, Legendre P, Ohara B, Stevens MHH. Vegan: community ecology package. R package version 1.8.8. 2007. http://r-forge.r-project.org/ projects/vegan.
83. Peres-Neto PR, Legendre P, Dray S, Borcard D. Variation partitioning of species data matrices: Estimation and comparison of fractions. Ecology. 2006;87:2614-25.

84. Legendre P, Fortin MJ. Comparison of the Mantel test and alternative approaches for detecting complex multivariate relationships in the spatial analysis of genetic data. Mol Ecol Resources. 2010;10:831-44.

85. Legendre P, Fortin MJ, Borcard D. Should the Mantel test be used in spatial analysis? Methods Ecol Evol. 2015. doi:10.1111/2041-210X.12425.

86. Johnson JB, Omland KS. Model selection in ecology and evolution. Trends Ecol Evol. 2004;19:101-8.

87. Arnold TW. Uninformative parameters and model selection using Akaike's information criterion. J Wildlife Manage. 2010;74:1175-8.

88. Hey J. Isolation with migration models for more than two populations. Mol Biol Evol. 2010;27:905-20

89. Hey J, Nielsen R. Integration within the Felsenstein equation for improved Markov chain Monte Carlo methods in population genetics. Proc Nat Acad Sci USA. 2007:104:2785-90

90. Hudson RR, Kaplan NL. Statistical properties of the number of recombination events in the history of a sample of DNA sequences. Genetics. 1985;111:147-64.

91. Won YJ, Hey J. Divergence Population Genetics of Chimpanzees. Mol Biol Evol. 2004;22:297-307.

92. Peters J, Zhuravlev Y, Fefelov I, Logie A, Omland KE. Nuclear loci and coalescent methods support ancient hybridization as cause of mitochondrial paraphyly between gadwall and falcated duck (Anas spp.). Evolution. 2007;61: 1992-2006.

93. Burnham KP, Anderson DR. Model selection and multimodel inference. New York: Springer; 2002

94. García-Moreno J, Arctander P, Fjeldså J. Strong diversification at the treeline among Metallura hummingbirds. Auk. 1999;116:702-11.

95. Gutiérrez-Pinto N, Cuervo AM, Miranda J, Pérez-Emán J, Brumfield RT, Cadena CD. Non- monophyly and deep genetic differentiation across low-elevation barriers in a Neotropical montane bird (Basileuterus tristriatus; Aves: Parulidae). Mol Phylogenet Evol. 2012;64:56-165.

96. Valderrama E, Pérez-Emán JL, Brumfield RT, Cuervo AM, Cadena CD. The influence of the complex topography and dynamic history of the montane Neotropics on the evolutionary differentiation of a cloud forest bird (Premnoplex brunnescens, Furnariidae). J Biogeogr. 2014;41:1533-46.

97. Parker III TA, Schulenberg TS, Graves GR, Braun MJ. The avifauna of the Huancabamba region. Northern Peru Ornithological Monographs. 1985;36:169-97.

98. Bates JM, Zink RM. Evolution into the Andes: molecular evidence for species relationships in the genus Leptopogon. Auk. 1994;111:507-15.

99. Smith FA, Betancourt JL, Brown JH. Evolution of body size in the woodrat over the past 25,000 years of climate change. Science. 1995;270:2012-4.

100. Zink RM, Remsen Jr JV. Evolutionary processes and patterns of geographic variation in Birds. In: Johnton RF, editor. Current Ornithology. New York: Plenum Press; 1986. p. 1-69.

101. Francis CD, Guralnick RP. Fitting the bill: do different winter food resources influence juniper titmouse (Baeolophus ridgwayi) bill morphology? Biol J Linn Soc. 2010;101:667-79.

102. Greenberg R, Danner R, Olsen B, Luther D. High summer temperature explains bill size variation in salt marsh sparrows. Ecography. 2011;34:001-7.

103. Crispo E, Bentzen P, Reznick DN, Kinnison MT, Hendry AP. The relative influence of natural selection and geography on gene flow in guppies. Mol Ecol. 2006;15:49-62.

104. McRae BH, Beier P. Circuit theory predicts gene flow in plant and animal populations. Proc Nat Acad Sci USA. 2007;104:19885-90.

105. Schneider CJ, Smith TB, Larison B, Moritz C. A test of alternative models of diversification in tropical rainforests: ecological gradients vs. rainforest refugia. Proc Nat Acad Sci USA. 1999;96:13869-73.

106. Smith TB, Calsbeek R, Wayne RK, Holder KH, Pires D, Bardeleben C. Testing alternative mechanisms of evolutionary divergence in an African rain forest passerine bird. J Evolution Biol. 2004;18:257-68.

107. Smith TB, Thomassen HA, Freedman AH, Sehgal RNM, Buermann W, Saatchi $S$, et al. Patterns of divergence in the olive sunbird Cyanomitra olivacea (Aves: Nectariniidae) across the African rainforest-savanna ecotone. Biol J Linn Soc. 2011;103:821-35.

108. Kirschel A, Slabbekoorn H, Blumstein DT. Testing alternative hypotheses for evolutionary diversification in an African songbird: rainforest refugia versus ecological gradients. Evolution. 2011;65:3162-74.

109. Smith TB, Wayne RK, Girman DJ, Bruford MJ. A role for ecotones in generating rainforest biodiversity. Science. 1997;276:1855-7. 
110. Garant D, Forde SE, Hendry AP. The multifarious effects of dispersal and gene flow on contemporary adaptation. Funct Ecol. 2007;21:434-43.

111. Cruickshank TE, Hahn MW. Reanalysis suggests that genomic islands of speciation are due to reduced diversity, not reduced gene flow. Mol Ecol. 2014;23:3133-57.

112. Hey J, Chung Y, Sethuraman A. On the occurrence of false positives in tests of migration under an isolation-with-migration model. Mol Ecol. 2015;24: 5078-83.

113. Garzione CN, Hoke GD, Libarkin JC, Withers S, MacFadden B, Eiler J, et al. Rise of the Andes. Science. 2008;320:1304-7.

114. Heindl M, Schuchmann KL. Biogeography, geographical variation and taxonomy of the Andean hummingbird genus Metallura GOULD, 1847. J Ornithol. 1998;139:425-73.

115. Hagan AA, Heath JE. Regulation of heat loss in the duck by vasomotion in the bill. J Therm Biol. 1980:5:95-101.

116. Tattersall GJ, Andrade DV, Abe AS. Heat exchange from the toucan bill reveals a controllable vascular thermal radiator. Science. 2009:325:468-70.

117. Beuchat CA, Calder III WA, Braun EJ. The integration of osmoregulation and energy balance in hummingbirds. Physiol Zool. 1990;63:1059-81.

118. Grant PR, Grant BR. How and why species multiply: the radiation of Darwin's finches. Princeton: Princeton University Press; 2008.

119. Lomolino MV, van der Geer AA, Lyras GA, Palombo MR, Sax DF, Rozzi R. Of mice and mammoths: generality and antiquity of the island rule. J Biogeogr. 2013:40:1427-39.

120. van der Geer AA, Lyras GA, Lomolino MV. Body size evolution of palaeo-insular mammals: temporal variations and interspecific interactions. J Biogeogr. 2013; 40:1440-50

121. Temeles EJ, Linhart YB, Masonjones M, Masonjones HD. The role of flower width in hummingbird bill length-flower length relationships. Biotropica. 2002;34:68-80

122. Weir JT, Price TD. Limits to speciation inferred from times to secondary sympatry and ages of hybridizing species along a latitudinal gradient. Am Nat. 2012;177: 462-9.

123. Rabosky DL. Diversity-Dependence, Ecological speciation, and the role of competition in macroevolution. Annu Rev Ecol Syst. 2013:44:481-502.

124. García-Moreno J, Arctander P, Fjeldså J. A case of rapid diversification in the neotropics: phylogenetic relationships among Cranioleuca spinetails (Aves: Furnaraiidae). Mol Phylogenet Evol. 1999;12:273-81.

125. Weir JT. Divergent timing and patterns of species accumulation in lowland and highland Neotropical birds. Evolution. 2006;60:842-55.

126. Beckman EJ, Witt CC. Phylogeny and biogeography of the New World siskins and goldfinches: rapid, recent radiation in the Central Andes. Mo Phylogenet Evol. 2015;87:28-45.

\section{Submit your next manuscript to BioMed Central and we will help you at every step:}

- We accept pre-submission inquiries

- Our selector tool helps you to find the most relevant journal

- We provide round the clock customer support

- Convenient online submission

- Thorough peer review

- Inclusion in PubMed and all major indexing services

- Maximum visibility for your research

Submit your manuscript at www.biomedcentral.com/submit

C Biomed Central 